\title{
Osteomeles schwerinae Extract and Its Major Compounds Inhibit Methylglyoxal-Induced Apoptosis in Human Retinal Pigment Epithelial Cells
}

\author{
Bo-Jeong Pyun ${ }^{1,+}{ }^{\oplus}$, Young Sook Kim ${ }^{2, *,+}$, Ik Soo Lee ${ }^{2}$, Dong Ho Jung ${ }^{1}$, Joo-Hwan Kim ${ }^{3}$ (D) \\ and Jin Sook Kim ${ }^{1, *}$ \\ 1 Herbal Medicine Division, Korea Institute of Oriental Medicine, 1672 Yuseongdae-ro, Yuseong-gu, \\ Daejeon 34054, Korea; bjpyun@kiom.re.kr (B.-J.P.); jdh9636@kiom.re.kr (D.H.J.) \\ 2 Research Infrastructure Team, Herbal Medicine Division, Korea Institute of Oriental Medicine, \\ Daejeon 34054, Korea; knifer48@kiom.re.kr \\ 3 Department of Life Science, Gachon University, Seongnam, Kyonggi-do 13120, Korea; \\ kimjh2009@gachon.ac.kr \\ * Correspondence: ykim@kiom.re.kr (Y.S.K.); jskim@kiom.re.kr (J.S.K.) \\ + These authors contributed equally to this work.
}

Academic Editor: Masahide Hamaguchi

Received: 29 April 2020; Accepted: 31 May 2020; Published: 3 June 2020

\begin{abstract}
The accumulation and formation of advanced glycation end products (AGEs) are related to diabetes and age-related disease. Osteomeles schwerinae C. K. Schneid. (Rosaceae, OSSC) is used traditionally for the treatment of various diseases in Asia. Previous studies have shown that OSSC elicits preventive effects in an in vivo model of diabetes. This study was to evaluate the antiapoptotic effects of dried leaves and twigs of OSSC extract and its major compounds in ARPE-19 cells-spontaneously arising human retinal pigment epithelial cells-under diabetic conditions. To examine the effects of an OSSC extract and its active compounds (acetylvitexin, hyperoside and quercitrin) on apoptosis in methylglyoxal (MG, the active precursor in the formation of AGEs)-treated ARPE-19 cells and the mechanism by which these effects occur, apoptosis was measured using flow cytometry analysis. Protein expression levels of phospho-p53 (p-p53), Bax and Bcl-2 were determined by western blot analyses. The OSSC extract inhibited apoptosis in MG-treated ARPE-19 cells in a dose-dependent manner. The major compounds also reduced the rate of apoptosis. Both the extract and major compounds also inhibited the expression of p-p53 and Bax and increased the levels of Bcl-2 that had been previously reduced by MG treatment. The OSSC extract $(0.1 \mu \mathrm{g} / \mathrm{mL})$ and its major compounds $(0.01 \mu \mathrm{M})$ attenuated apoptosis in ARPE-19 cells under toxic diabetic conditions by downregulating of expression of p-p53 and Bax. OSSC may serve as an alternative therapy to retard the development of diabetic retinopathy.
\end{abstract}

Keywords: Osteomeles schwerinae; diabetic retinopathy; methylglyoxal; apoptosis; human retinal pigment epithelial cells

\section{Introduction}

The accumulation of advanced glycation end products (AGEs) is accelerated under conditions of chronic hyperglycemia and many age-related diseases [1]. Retinal pigment epithelial cells (ARPE-19 cells) are critical for the maintenance and survival of photoreceptors, as well as for the apoptosis of the RPE (retinal pigment epithelium) related to oxidative stress, inflammation and AGEs [2-4]. Methylglyoxal (MG), a highly reactive dicarbonyl compound, is an AGE precursor whose levels have been shown to increase in experimental and clinical diabetes [1]. Elevated MG levels have been shown to induce reactive oxygen species (ROS) production and apoptosis in various 
cell types [5-7]. Current research is focused on therapeutic and nutritional interventions to prevent apoptosis in diabetic retinopathy (DR) [8].

Osteomeles schwerinae C. K. Schneid. (OSSC), belonging to the family Rosaceae, is a perennial evergreen shrub, native to China that is harvested in the wild and used for local food [9]. Furthermore, this plant that has been used as a traditional Chinese medicine for the treatment of laryngopharyngitis, diarrhea, dysentery, folliculitis and hyperglycemia [10,11]. Previous studies have shown that OSSC ameliorates retinal endothelial cell apoptosis via the regulation of AGEs accumulation in the spontaneously diabetic torii rats [6,12]. Hyperoside, a compound of OSSC extract, has demonstrated significant inhibition of aldose reductase [13], the key enzyme in the polyol pathway during the pathogenesis of diabetic cataracts [14]. Furthermore, herbal extracts and their major compounds have been used for the treatment of diabetes and diabetic complications [15].

Here, we investigated whether an OSSC extract and its maker compounds could inhibit apoptosis in ARPE-19 cells treated with MG, thereby demonstrating their potential use to prevent the development of DR by inhibiting apoptosis in cultured RPE under toxic diabetic conditions.

\section{Results}

\subsection{Effects of the OSSC Extract and Its Major Compounds on the Viability of MG-Treated Cells}

After treatment with $500 \mu \mathrm{M}$ MG for $24 \mathrm{~h}$, cell viability was not significantly changed. However, at a concentration of $1000 \mu \mathrm{M}$, cell viability was significantly decreased to $65 \%$ (Figure 1A). FITC-conjugated annexin $\mathrm{V}$ and PI were used to monitor the progression of apoptosis. The percentage of early apoptotic (annexin $\mathrm{V}$ positive/PI negative) and late apoptotic/necrotic cells (annexin V positive-negative /PI positive) were determined. As shown in Figure 1B, the percentage of apoptotic cells was significantly increased from $6.11 \%$ (control) to $99.68 \%$ (at $5 \mathrm{mM} \mathrm{MG}$ ). MG increased the rate of apoptosis in a concentration-dependent manner.

In a previous study, the purities of maker compounds of OSSC extract were analyzed by HPLC [12]. Here, we evaluated whether the extract and its maker compounds could affect cell viability in MG-treated ARPE-19 cells. As shown in Figure 1C, MG inhibited cellular proliferation, and pretreatment with the OSSC extract and its maker compounds significantly attenuated this inhibitory effect.

\subsection{Effects of the OSSC Extract and Its Maker Compounds on MG-Induced Apoptosis}

As shown in Figure 2A,B, MG increased the rate of apoptosis up to $30 \%$; the OSSC extract and each maker compound attenuated the MG-induced increase in apoptosis. The effects of hyperoside were indistinguishable from the normal control. To assess the effects of the OSSC extract and its maker compounds on apoptosis-related factors involved in apoptosis, we examined the expression levels of p-p53, Bax and Bcl-2 by western blot analysis. MG induced a 2.3- and 1.4-fold increase in the expression of p-p53 and Bax, whereas the OSSC extract and its major compounds reduced the levels of these factors. Bcl-2 levels were reduced 0.8-fold after MG treatment, whereas the OSSC extract and its maker compounds increased Bcl-2 levels (Figure 2C).

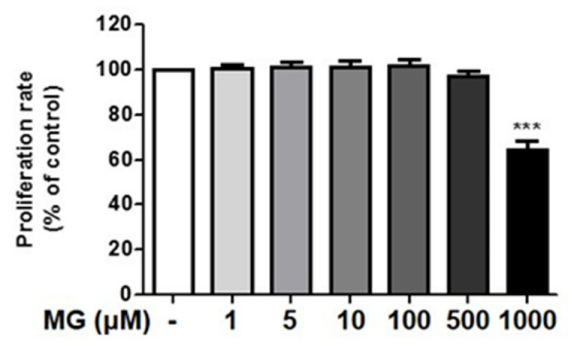

(A)

Figure 1. Cont. 

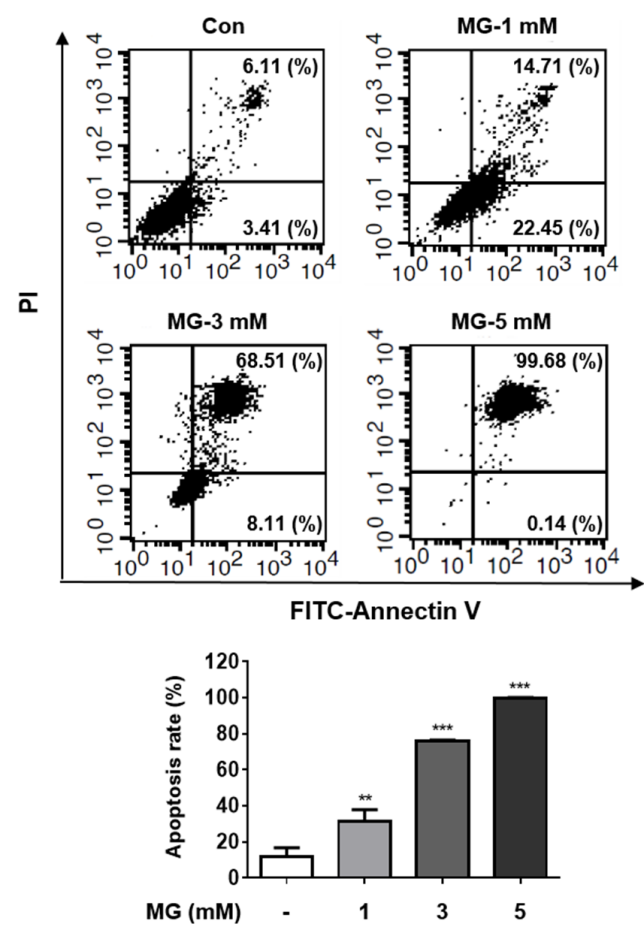

(B)

C)
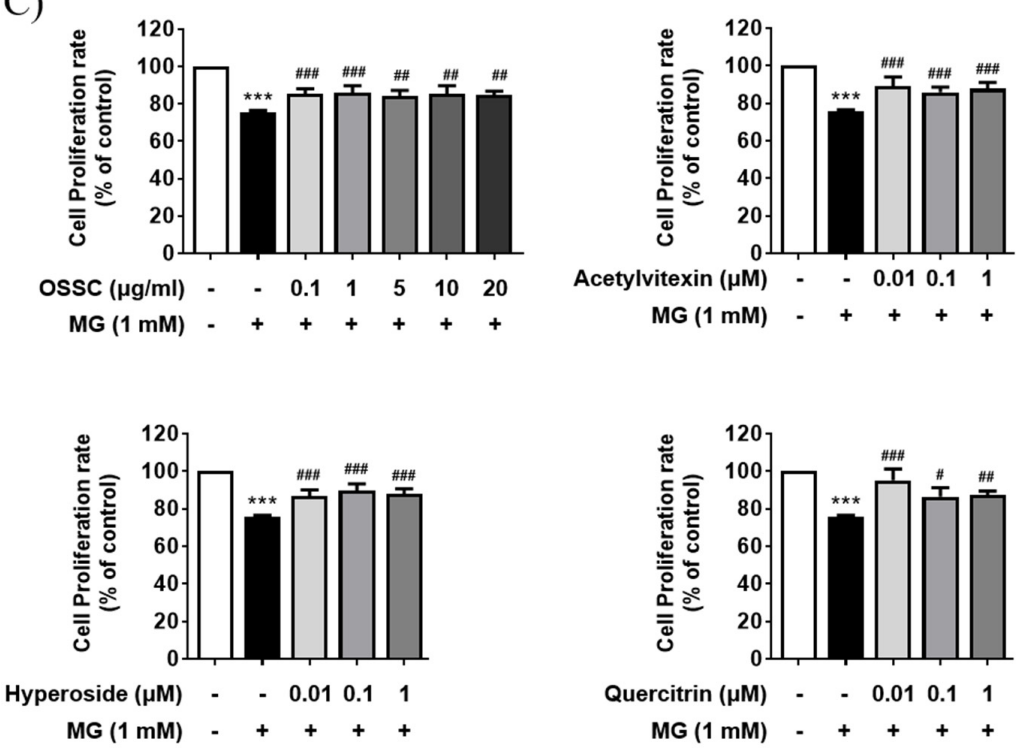

Figure 1. Effects of the Osteomeles schwerinae C. K. Schneid. (OSSC) extract and its major compounds on the viability of methylglyoxal (MG)-treated cells; (A) proliferation rates. Data are representative of three independent experiments and are expressed as the mean \pm S.E.M. $(n=4)$. ${ }^{* * *} P<0.01$ vs. control; (B) FACS analysis. ${ }^{* * *} P<0.01,{ }^{* *} P<0.05$ vs. control, respectively; (C) proliferation rates after treatment with the OSSC extract $(0.1-20 \mu \mathrm{g} / \mathrm{mL})$ and its major compounds $(0.01-1 \mu \mathrm{M}){ }^{* * *} P<0.001 \mathrm{vs}$. control; ${ }^{\# \# \# ~} P<0.001,{ }^{\# \#} P<0.01,{ }^{\#} P<0.05$ vs. MG, respectively. 

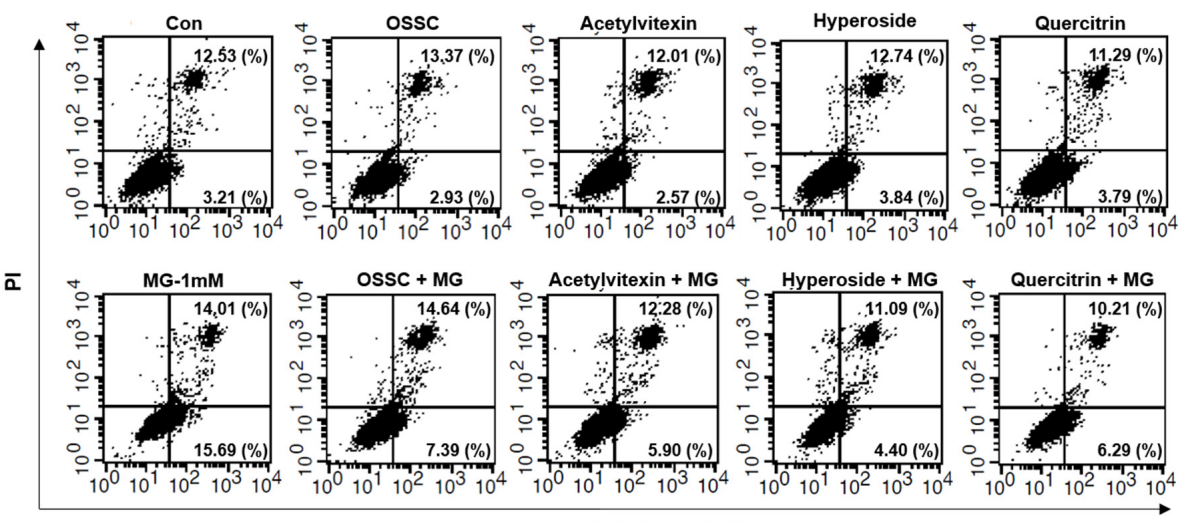

(A)
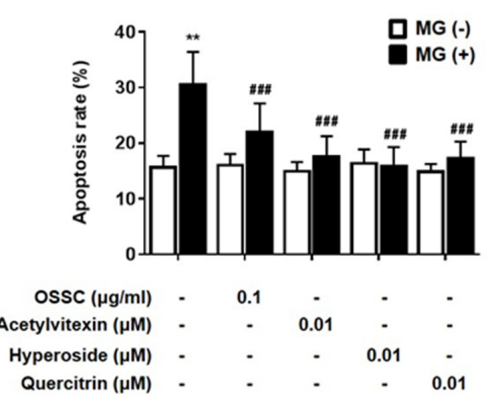

(B)

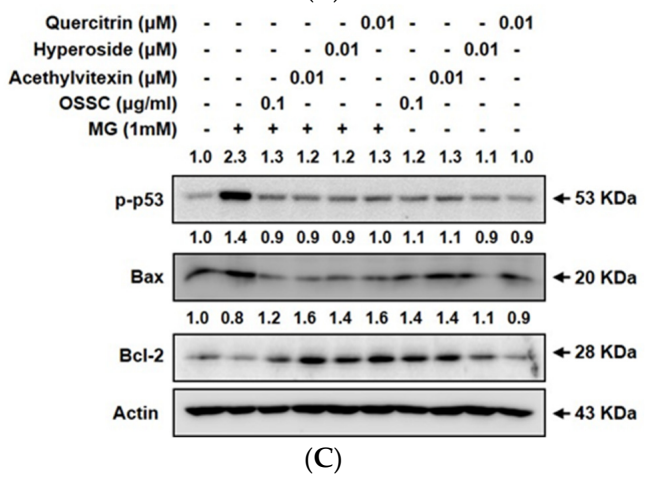

Figure 2. Effects of the OSSC extract and its maker compounds on MG-induced apoptosis. (A) Annexin $\mathrm{V}$ and PI staining; (B) percent rate of apoptosis. Data are expressed as the mean \pm S.E.M. $(n=3)$. ** $P<0.01$ vs. control; ${ }^{\# \# ~} P<0.001$ vs. MG; (C) expression of apoptosis-related proteins (p-p53, Bax and Bcl-2). Actin as the loading control.

\section{Discussion}

Herbal extracts and natural compounds have traditionally been used to treat diabetes and diabetic complications $[8,12,16,17]$. Here, an OSSC extract and its maker compounds were tested for their inhibitory effects on apoptosis and its related mechanisms under toxic diabetic conditions in ARPE-19 cells. The results showed that the OSSC extract and its maker compounds significantly inhibited apoptosis under diabetic conditions. MG-induced p53 phosphorylation and Bax-1 expression were reduced by OSSC treatment of ARPE-19 cells. Bcl-2 expression that had been attenuated by MG was increased by OSSC treatment in ARPE-19 cells.

Diabetic retinopathy gives rise to apoptosis in several retinal cell types, especially retinal pericytes and ARPE-19 cells [18]. The levels of several factors, such as glucose, ROS and AGEs, are elevated in diabetes and accelerate cellular injury and apoptosis [19,20]. Levels of MG are increased under diabetic conditions via a glucose-related mechanism and modification of lysine and arginine residues. Strategies to treat or prevent diabetic complications with medicinal herbs have focused on the inhibition 
of AGEs formation or its downstream pathways. The three maker compounds of the OSSC extract are 2'-O-acetylvitexin, hyperoside and quercitrin [6,21]; 2'-O-acetylvitexin was first isolated and characterized in Trollius (a genus of about 30 species of flowering plants), but no data previously exist with regard to its activity [22]. This study reveals the antiapoptotic activity of acetylvitexin in ARPE-19 cells under toxic diabetic conditions for the first time (Figure 2). Hyperoside is the predominant phenolic compound in the OSSC extract and inhibits oxidative stress via the activation of heme oxygenase-1 (HO-1) [23]. Quercitrin has been shown to elicit beneficial effects on diabetes, especially the inhibition of both aldose reductase activity and AGEs formation and the reduction of blood glucose levels $[24,25]$. These results suggest that the OSSC extract and its maker compounds may prevent the apoptosis of RPE cells under diabetic conditions.

\section{Materials and Methods}

\subsection{Preparation of the OSSC Extract and Its Major Compounds}

O. schwerinae was collected from Shrubs (2000 m), Kunming, Fuming County, China, in September 2013 and identified by Prof. J.-H. Kim, Gachon University, Republic of Korea. A voucher specimen (No. DiAB-2006-141) was deposited in the Herbarium of Korea Institute of Oriental Medicine, Republic of Korea. Dried leaves and twigs of $O$. schwerinae $(1.0 \mathrm{~kg})$ extract and its major compounds [2'-O-acetylvitexin $\left(4.2 \mathrm{mg}, t_{\mathrm{R}} 18.3 \mathrm{~min}\right)$, quercitrin $\left(12 \mathrm{mg}, t_{\mathrm{R}} 22.8 \mathrm{~min}\right)$ and hyperoside $(7 \mathrm{mg}$, $t_{\mathrm{R}} 28.5 \mathrm{~min}$ )] were further purified, as previously described [15]. To check the its major compounds, high-performance liquid chromatography (HPLC) analysis was performed using an Agilent 1200 HPLC instrument chromatogram of OSSC. The column temperature was maintained at $30^{\circ} \mathrm{C}$. The analysis was performed at a flow rate of $1.0 \mathrm{~mL} / \mathrm{min}$ and monitored at UV254 $\mathrm{nm}$ [15].

\subsection{Cell Culture}

The ARPE-19 cells were purchased from the American Type Culture Collection (ATCC CRL-2302; Manassas, VA, USA) and maintained at $37{ }^{\circ} \mathrm{C}$ in a humidified $5 \% \mathrm{CO}_{2}$ incubator, as previously described [25].

\subsection{Determination of Apoptosis Using Flow Cytometry}

The rate of apoptosis was examined by flow cytometry using an annexin V-fluorescein isothiocyanate (FITC) and propidium iodide (PI) apoptosis detection kit (BD Bioscience, San Jose, CA, USA) following the manufacturer's protocol. ARPE-19 cells were placed into 6-well plates at the density of $2.5 \times 10^{5}$ cells/well were treated with $1 \mathrm{mM} \mathrm{MG}$ in the presence or absence of OSSC extract and its major compound for $24 \mathrm{~h}$. Following digestion with trypsin and washing twice with PBS, the cells were labeled with $5 \mu \mathrm{L}$ Annexin V-FITC and $5 \mu \mathrm{L}$ PI for 5 min each at room temperature for $15 \mathrm{~min}$ in the dark. After incubation, $400 \mathrm{~mL}$ binding buffer was added and the percentage of apoptotic cells was analyzed using a FACSCalibur flow cytometer (BD Biosciences, Franklin Lakes, NJ, USA).

\subsection{Western Blot Analysis}

Polyacrylamide gel electrophoresis was performed, as described previously [25]. Membranes were probed with polyclonal antibodies against phosphorylated p53 (p-p53; Santa Cruz, CA, USA), Bax and Bcl-2 (Cell Signaling, Beverly, MA, USA), each at a 1:1000 dilution. The signals were detected using a WEST-one ECL solution (Intron, Korea) and captured on Fuji film LAS-3000 (Tokyo, Japan).

\subsection{Statistical Analysis}

Data are expressed as the mean \pm S.E.M. ANOVA with Tukey's test was used for multiple comparisons using Prism 5.04 software (GraphPad, San Diego, CA, USA). 


\section{Conclusions}

In conclusion, we measured the antiapoptotic activities of the OSSC extract $(0.1 \mu \mathrm{g} / \mathrm{mL})$ and its three major compounds $(0.01 \mu \mathrm{M})$ on MG-treated ARPE-19 cells, finding that the expression of the apoptotic factors p-p53, Bax and Bcl-2 was attenuated. Taken together, these results suggest that the use of the OSSC extract and its major compounds could prevent the development of DR.

\section{Patents}

The patents related to this study were registered in Kore (No. 10-097394), China (No. XL200980160639.3), Hong Kong (No. HK1170958), England, France, Swiss, Germany (No. 247483), the United Arab Emirates (No. 1028) and the USA (No. 8784,911).

Author Contributions: B.-J.P. and D.H.J. performed the cell experiments; Y.S.K. designed the experiments and wrote and edited the manuscript; I.S.L. prepared the samples; J.-H.K. collected and identified the plants; and J.S.K. supervised the work and reviewed the manuscript. All authors provided comments on the initial and final drafts of the manuscript. All authors have read and agreed to the published version of the manuscript.

Funding: This research was supported by the KIOM (grants K16270 and KSN1911711).

Conflicts of Interest: We wish to confirm that there are no known conflicts of interest associated with this publication and there was no significant financial support for this work that could have influenced its outcome.

\section{References}

1. Goh, S.Y.; Cooper, M.E. Clinical review: The role of advanced glycation end products in progression and complications of diabetes. J. Clin. Endocrinol. Diabetes 2008, 93, 1143-1152.

2. Cai, J.; Nelson, K.C.; Wu, M.; Sternberg, P., Jr.; Jones, D.P. Oxidative damage and protection of the RPE. Prog. Retin. Eye Res. 2000, 19, 205-221.

3. Wang, Y.; Shen, D.; Wang, V.M.; Yu, C.R.; Wang, R.X.; Tuo, J.; Chan, C.C. Enhanced apoptosis in retinal pigment epithelium under inflammatory stimuli and oxidative stress. Apoptosis 2012, 17, 1144-1155. [CrossRef] [PubMed]

4. Wang, P.; Xing, Y.; Chen, C.; Chen, Z; Qian, Z. Advanced glycation end-product (AGE) induces apoptosis in human retinal ARPE-19 cells via promoting mitochondrial dysfunction and activating the Fas-FasL signaling. Biosci. Biotechnol. Biochem. 2016, 80, 250-256. [CrossRef]

5. Kim, K.M.; Kim, Y.S.; Jung, D.H.; Lee, J.; Kim, J.S. Increased glyoxalase I levels inhibit accumulation of oxidative stress and an advanced glycation end product in mouse mesangial cells cultured in high glucose. Exp. Cell Res. 2012, 318, 152-159. [CrossRef] [PubMed]

6. Kim, Y.S.; Jung, D.H.; Lee, I.S.; Pyun, B.J.; Kim, J.S. Osteomeles schwerinae extracts inhibits the binding to receptors of advanced glycation end products and TGF-beta1 expression in mesangial cells under diabetic conditions. Phytomedicine 2016, 23, 388-397. [CrossRef]

7. Yuan, J.; Zhu, C.; Hong, Y.; Sun, Z.; Fang, X.; Wu, B.; Li, S. The role of cPLA2 in Methylglyoxal-induced cell apoptosis of HUVECs. Toxicol. Appl. Pharm. 2017, 323, 44-52. [CrossRef]

8. Song, M.K.; Roufogalis, B.D.; Huang, T.H.W. Modulation of diabetic retinopathy pathophysiology by natural medicines through PPAR-gamma-related pharmacology. Br. J. Pharm. 2012, 165, 4-19. [CrossRef]

9. Geng, Y.; Zhang, Y.; Ranjitkar, S.; Huai, H.; Wang, Y. Traditional knowledge and its transmission of wild edibles used by the Naxi in Baidi Village, northwest Yunnan province. J. Ethnobiol. Ethnomed. 2016, 12, 10. [CrossRef]

10. Hsieh, C.-F.; Chaw, S.-M. Osteomeles schwerinae CK Schneid. (Rosaceae): A new record for the flora of Taiwan. Bot. Bull. Acad. Sin. 1996, 37, 281-285.

11. Song, L.; Hu, L.; Hong, X.J.S.S. Chinese Materia Medica; Technology Press: Shanghai, China, 1999; Volume 4, p. 166.

12. Kim, C.S.; Kim, J.; Kim, Y.S.; Jo, K.; Lee, Y.M.; Jung, D.H.; Lee, I.S.; Kim, J.H.; Kim, J.S. Improvement in Diabetic Retinopathy through Protection against Retinal Apoptosis in Spontaneously Diabetic Torii Rats Mediated by Ethanol Extract of Osteomeles schwerinae C.K. Schneid. Nutrients 2019, 11, 546. [CrossRef] 
13. Lee, J.; Jang, D.S.; Yoo, N.H.; Lee, Y.M.; Kim, J.-H.; Kim, J.S. Single-step separation of bioactive flavonol glucosides from Osteomeles schwerinae by high-speed counter-current chromatography. J. Sep. Sci. 2010, 33, 582-586. [CrossRef]

14. Brownlee, M. Biochemistry and Molecular Cell Biology of Diabetic Complication. Nature 2001, 14, 813-820. [CrossRef]

15. Veeresham, C.; Rama Rao, A.; Asres, K. Aldose reductase inhibitors of plant origin. Phytother. Res. 2014, 8, 317-33. [CrossRef]

16. Marles, R.J.; Farnsworth, N.R. Antidiabetic plants and their active constituents. Phytomedicine 1995, 2, 137-89. [CrossRef]

17. Rao, B.K.; Kesavulu, M.M.; Giri, R.; Appa Rao, C. Antidiabetic and hypolipidemic effects of Momordica cymbalaria Hook. fruit powder in alloxan-diabetic rats. J. Ethnopharmacol. 1999, 67, 103-109. [PubMed]

18. Feenstra, D.J.; Yego, E.C.; Mohr, S. Modes of Retinal Cell Death in Diabetic Retinopathy. J. Clin. Exp. Ophthalmol. 2013, 4, 298. [PubMed]

19. Giacco, F.; Brownlee, M. Oxidative stress and diabetic complications. Circ. Res. 2010, 107, 1058-1070. [CrossRef]

20. Volpe, C.M.O.; Villar-Delfino, P.H.; Dos Anjos, P.M.F.; Nogueira-Machado, J.A. Cellular death, reactive oxygen species (ROS) and diabetic complications. Cell Death Dis. 2018, 9, 119. [CrossRef]

21. Kim, Y.S.; Jung, D.H.; Lee, I.S.; Choi, S.J.; Yu, S.Y.; Ku, S.K.; Kim, M.H.; Kim, J.S. Effects of Allium victorialis leaf extracts and its single compounds on aldose reductase, advanced glycation end products and TGF-beta1 expression in mesangial cells. BMC Complement. Altern. Med. 2013, 13, 251. [CrossRef]

22. Wu, L.Z.; Zhang, X.P.; Xu, X.D.; Zheng, Q.X.; Yang, J.S.; Ding, W.L. Characterization of aromatic glycosides in the extracts of Trollius species by ultra high-performance liquid chromatography coupled with electrospray ionization quadrupole time-of-flight tandem mass spectrometry. J. Pharm. Biomed. Anal. 2013, 75, 55-63. [CrossRef] [PubMed]

23. Park, J.Y.; Han, X.; Piao, M.J.; Oh, M.C.; Fernando, P.M.; Kang, K.A.; Ryu, Y.S.; Jung, U.; Kim, I.G.; Hyun, J.W. Hyperoside Induces Endogenous Antioxidant System to Alleviate Oxidative Stress. J. Cancer Prev. 2016, 21, 41-47. [CrossRef] [PubMed]

24. Yang, D.K.; Kang, H.S. Anti-Diabetic Effect of Cotreatment with Quercetin and Resveratrol in Streptozotocin-Induced Diabetic Rats. Biomol. Ther. 2018, 26, 130-138. [CrossRef] [PubMed]

25. Kim, Y.S.; Jung, D.H.; Kim, N.H.; Lee, Y.M.; Jang, D.S.; Song, G.Y.; Kim, J.S. KIOM-79 inhibits high glucose or AGEs-induced VEGF expression in human retinal pigment epithelial cells. J. Ethnopharmacol. 2007, 112, 166-172. [CrossRef] [PubMed]

Sample Availability: Samples of the compounds are available from the authors.

(C) 2020 by the authors. Licensee MDPI, Basel, Switzerland. This article is an open access article distributed under the terms and conditions of the Creative Commons Attribution (CC BY) license (http://creativecommons.org/licenses/by/4.0/). 